\title{
MODAS OCULTAS. UNA APROXIMACIÓN CUALITATIVA A FENÓMENOS OCULTISTAS
}

\section{HIDDEN FASHION. A QUALITATIVE APPROACH TO OCCULT PHENOMENA}

\section{AUTORES}

Ana Alegre: Socióloga. Autora de variados artículos de análisis social y ponente en numerosos Congresos.

ana.alegre@mixmail.com

Felipe Barral: Productor de la CNN en Español. Escritor y conferenciante. felipe.barral@ozu.es

David P. Benito: Profesor en la Universidad Pública de Navarra (España) de Tecnología Electrónica. Director de Área de Innovación Educativa de la Universidad Pública de Navarra (España), dependiente del Vicerrectorado de Enseñanzas. david.benito@arrakis.es

Pablo Palacio: Sociólogo. Estudioso de los fenómenos comunicativos de masas y experto en audovisuales y publicidad.

ppalacio72@teleline.es

\section{CURRÍCULUM VITAE}

Ana Alegre: Socióloga. Autora de variados artículos de análisis social y ponente en numerosos Congresos.

Felipe Barral: Productor de la CNN en Español. Escritor y conferenciante.

David P. Benito: Profesor en la Universidad Pública de Navarra (España) de Tecnología Electrónica. Director de Área de Innovación Educativa de la Universidad Pública de Navarra (España), dependiente del Vicerrectorado de Enseñanzas.

Pablo Palacio: Sociólogo. Estudioso de los fenómenos comunicativos de masas y experto en audovisuales y publicidad. 


\title{
RESUMEN
}

Desde la última guerra hay en los Estados Unidos más de treinta mil astrólogos, veinte revistas consagradas únicamente a la astrología, de las cuales una tira alrededor de los quinientos mil ejemplares. Más de dos mil periódicos diarios tienen una sección astrológica. En 1943 cinco millones de americanos actuaban según las directrices de adivinos y gastaban doscientos millones de dólares para conocer el porvenir.

\section{PALABRAS CLAVE}

Moda - Fenómenos ocultistas - Astrología

\begin{abstract}
Since the last war was in the United States more than thirty thousand astrologers, twenty journals devoted solely to astrology, from which a strip about five hundred thousand copies. Over two thousand daily newspapers have a section astrological. In 1943 five million Americans were acting under the guidelines of soothsayers and spent two hundred million dollars to know the future.
\end{abstract}

\section{KEY WORDS}

Clothing - Phenomena Occult - Astrology

\section{ÍNDICE}

1. Introducción

2. Establecimiento del corpus publicitario 
3. Análisis de los códigos implícitos

4. Categorías publicitarias

\section{Introducción}

Desde la última guerra hay en los Estados Unidos más de treinta mil astrólogos, veinte revistas consagradas únicamente a la astrología, de las cuales una tira alrededor de los quinientos mil ejemplares. Más de dos mil periódicos diarios tienen una sección astrológica. En 1943 cinco millones de americanos actuaban según las directrices de adivinos y gastaban doscientos millones de dólares para conocer el porvenir.

Sólo Francia cuenta con cuarenta mil curanderos y más de cincuenta mil gabinetes de consulta de carácter ocultista. Según cálculos controlados, en París, los honorarios de adivinos, pitonisas, videntes, radioestesistas, curanderos, etc. alcanzaban los cincuenta mil millones de francos. Para toda Francia el montante de la Magia en 1960 era de unos trescientos mil millones de francos...; mucho más de lo que se destinaba a investigación científica.

El estado de la cuestión parece seguir por semejantes derroteros incluso en España: el horóscopo es la segunda página del teletexto más consultada, prácticamente la totalidad de las publicaciones periódicas llevan en sus páginas algún tipo de sección de consulta paranormal... Según el Centro de Estudios Sociológicos (1999) la caída de la creencia en Dios de los jóvenes se ve compensada por el auge en su creencia en la adivinación y astrología (el 56\% de los jóvenes encuestados así lo afirma). 
Aparecen en los últimos años nuevos procesos ofrecidos por los mecanismos de consumo; los videntes aprovechan el espacio televisivo para anunciar servicios esotéricos por vía telefónica. Los más famosos son dueños de empresas dedicadas al negocio de lo oculto. Al habla con el director de Recursos Humanos del holding mántico propiedad por dos conocidos adivinos, este describía que en las respectivas empresas no bajaban en ningún momento de una treintena de trabajadores, principalmente empleados en tareas de adivinación telefónica.

Son datos que parecen invitar a la curiosidad a desviar recursos hacia este ámbito. Puede llegar a resultar fascinante abordar la cuestión de cómo acaban por resultar compatibles un progreso cultural evidente (ante el avance tecnológico y la conquista de libertades individuales)y la permanencia de prácticas en las que no hay reparo en calificar de ocultistas. Avanzan de inmediato cuestiones como la de preguntarse por la clase de estructuras sociales y/o psicológicas que soportan no sólo tales prácticas sino una la creencia que en este campo más que en otros parece ser incuestionable. ¿Realmente existe tal impacto de lo oculto en una sociedad contemporánea como la española? ¿Cómo recibe una sociedad moderna esta fractura entre dos conocimientos que conviven en el quehacer diario de millones de personas? ¿Cómo un sujeto socializado resuelve unas más que esperables disonancias entre mensajes divergentes?

No son las únicas y quizá tampoco las más importantes preguntas, pero quizá observar la evolución del objeto estudiado en la consideración de los investigadores revele preguntas que permanecen latentes en el espíritu mismo del trabajo. El abordaje en un primer momento atendía a los aspectos más formales de la creencia en influjos de los astros. Sin embargo, establecer una tipología en la que unas pocas variables descriptivas de los sujetos indicaran relaciones con un nivel más o menos profundo de creencia en la Astrología se revelaba como un hecho parcial en un 
campo considerablemente más amplio, en el que diferentes técnicas adivinatorias eran practicadas por personas como las entrevistadas para satisfacer unas quién sabe qué necesidades.

Pudiéramos enzarzarnos en una de las más clásicas logomaquias de la antropología y de la sociología y empezar delimitando, sirviéndonos de los maestros de éstas y de otras disciplinas, el ámbito de la realidad que acotan conceptos como Magia o la dimensión práctica en la escenografía social de conceptos como Ocultismo. Pero en vez de acudir a Tylor, Frazer, Durkheim, Marett, Malinowsky... desde un principio, hemos pretendido que sea la realidad, siempre cambiante, de nuestro objeto la que acabe por perfilar y acabar limitando el alcance de estas prácticas. Buscamos en la práctica diaria de estas cuestiones las herramientas que resulten de mayor utilidad a nuestros intereses. Así, una aproximación a la publicidad permite que sean los spots los que sugieran los listados que acaban por establecer la afinidad de las disciplinas ocultistas; el discurso de los entrevistados enlazarán fenómenos que no hubiéramos podido considerar si nos hubiéramos atenido desde el comienzo a las definiciones tradicionales de Magia y Ocultismo.

Así, lo que en principio era un interés de profilaxis sociológica, en el que sólo cabía establecer relaciones (más correlaciones) entre niveles de variables directamente observables (formación académica, edad, sexo, estatus...) y las diferentes prácticas soteriológicas, ha acabado por ser un intento de profundizar en las estructuras que permitan entender las relaciones íntimas que establecen los sujetos con el producto/práctica. Cabe preguntarse por el funcionamiento ulterior, más allá del vaticinio. Cabe la cuestión de los deseos, de las necesidades que sacian estas vías de asesoramiento. ¿Cuáles son las carencias?

Encontramos un buen servicio en los conocimientos de corte psicodinámico de los movimientos psicológicos, que nos permiten profundizar en los discursos de los 
entrevistados y diseccionar los espacios televisivos de videncia en directo que se pueden observar en televisiones privadas como la de ámbito regional Telemadroño. El análisis semiológico de R. Barthes nos servirá para desgranar los contenidos en el análisis del cuerpo publicitario.

Mas, ¿qué decir sobre la verdad del hecho de estas prácticas? Es un ejercicio necesario de honestidad exponer nuestra postura al respecto. Porque si bien la intención formalista es la de no implicación con la veracidad o falsedad de las informaciones que se proporcionan, este ejercicio de asepsia informativa parece encontrase en un delicado equilibrio entre nuestro aparataje conceptual, del que no nos podemos excluir, y un rigor necesario para distanciarnos lo suficiente como para que la que sigue no acabe siendo un ejercicio relajado de doxa. Pretendemos fidelidad a la postura de J. Caro Baroja, que hace explícita en su obra Vidas mágicas e inquisición:

¿Se puede creer que esta fe opera en el vacío, en pura ilusión o deseo, sin apoyo de experiencias, sin éxito factual alguno? A estas preguntas no he de responder; estoy tan apartado de la especulación teológica como de la parapsicológica y metapsíquica. Soy un historiador del mundo moral, del hombre metido en sociedad, lleno de deseos, de ilusiones, de pasiones, hoy como ayer. Si estas personas se ajustan o no a un mundo sobrenatural, o a un mundo en el que se dan hechos aún no controlados por la ciencia, no es asunto de mi incumbencia. Pero en tanto en cuanto pueda explicar los documentos que tengo a la vista a la luz del estudio de las puras pasiones humanas, no tengo por qué recurrir a más. 


\section{Establecimiento del corpus publicitario}

Abordamos en este punto el análisis de contenido de doce anuncios televisivos de servicios telefónicos mágicos (tarots, videncias, astrología, interpretación de sueños, etc.).

El hecho de restringir la elección de soporte publicitario al formato televisivo exclusivamente, obedece a motivos de índole pragmática; una primera aproximación a los espacios publicitarios de los tres medios a nuestra disposición (televisión, prensa diaria y prensa especializada) reveló la riqueza de contenidos gráficos, textuales y narrativos del anuncio televisivo frente al laconismo del anuncio estático (bien anuncio por palabras en prensa diaria o más elaborado en revistas del sector). Así decidimos utilizar el contenido del anuncio televisivo, pues éste prometía trabajar con más facilidad y profusión en el análisis del discurso publicitario, para obtener una geografía más completa de los topos comunes de la retórica del sector. Empleamos aquí la metodología barthesiana de análisis discursivo que nos facilitará explicitar aquellos elementos que permanecen implícitos

\section{Análisis de los códigos impl ícitos}

ANUNCIO 1: "El círculo de la amistad"

Una sintonía alegre abre el anuncio. En primer plano, con un fondo blanco y ocupando la totalidad de la pantalla, una pareja habla y sonríen. La cámara se desplaza hacia la izquierda y aparece una tercera mujer que se apoya en el hombro del joven y habla con él, quedando éste supuestamente entre las dos, pues ya es sólo visible el nuevo tamdem. 
Continúa el movimiento de la cámara y acompañado por el rostro de la $3^{a}$ mujer, que gira en la misma dirección. Se forma una nueva pareja esta vez entre la última mujer y una nueva. Todos los planos de los actores son medios planos superiores y podríamos situarlos en el margen de edad comprendida entre los 20 y 30 años.

Se abre el plano, el grupo queda atrás y entra en escena el busto de un nuevo joven. El margen superior e inferior tornan en negros; en la porción superior un cartel reza: "Tarot el círculo de la amistad", abajo "906.....".

El joven se acerca a la cámara y dice: "No afrontes más tus problemas solo, llámanos al Tarot del círculo de la amistad", " 906...." , "un amigo que te escucha"

El anuncio finaliza con la cara en primer plano del último joven y el grupo inicial al fondo charlando amistosamente.

En este spot, la retórica cinematográfica reproduce fielmente el lema de la empresa (tarot el círculo de la amistad); El desplazamiento progresivo entre gente que se habla y sonríe describe propiamente un grupo de amigos divirtiéndose, un círculo de amistad.

El texto del último actor, termina de cerrar el círculo incluyendo al espectador en la cadena: "No afrontes más tus problemas...". Es totalmente necesario el texto escrito que titula el anuncio para ubicar, definitivamente, el tipo de producto. En los momentos iniciales del anuncio al no disponer de ese referente podríamos pensar que nos enfrentamos, como poco a un teléfono de contactos. Ninguna clave visual o textual, referencias a prácticas esotéricas u objetos propios del esoterismo (la salud, dinero, etc) aparecen en el anuncio. Tan sólo la palabra Tarot desambigXa el mensaje completamente y nos ayuda a entender la finalidad del anuncio: publicitar un Tarot 
que nos permita enfrentarnos a los problemas con la ayuda de alguien más, un amigo.

No es el pasado, el presente o el futuro la solución para tus problemas, sino la compañía. Y eso es lo que vende nuestro anuncio, compañía. El texto del último actor es brutalmente sincero en lo que a eso se refiere: "No afrontes mas tus problemas solo... un amigo te escucha". El spot se desvincula así de las prácticas esotéricas tradicionales y ofrece, en una primera lectura, un servicio indistinguible del de un teléfono de contactos o, incluso, del de la línea de la esperanza.

Pero no olvidemos que a fin de cuentas se trata de un servicio mágico, y la palabra Tarot nos garantiza que el origen de nuestras citas, la soledad y nuestro deseo de compañía, se verán colmados en el acto marcando un número de teléfono, con la consecución de una vida social plena. Si el cliente además tiene orientación sexual masculina, un plus de fantasías acompaña a la oferta, pues la composición del círculo, tres mujeres y un hombre, su contacto y disposición puede dar rienda suelta a todo tipo de fantasías sexuales poligínicas.

\section{ANUNCIO 2: "Lara de Vina"}

Aparece una mujer morena, un poco gruesa, en una sala blanca, vestida con ropas amplias, de tonos claros.

Habla desde detrás de un escritorio también blanco, adornado con un libro, un florero y una bola de cristal, cartas de tarot y un teléfono. En la esquina superior derecha reza un nombre: "Lara de Vina". 
Voz de Lara: "Hola soy Lara de Vina y a partir de ahora voy a ser tu ángel de la guarda". "Después de 15 años de experiencia profesional he llegado a la conclusión de que mi verdadero secreto se basa en la confianza".

El plano de su cara se funde con los objetos del escritorio.

Voz de Lara "conseguiré quitarte todos tus miedos, todas tus ansiedades, conmigo te sentirás tan segura de todo y serás inmune a las señales". En sus manos Lara sujeta cartas de tarot.

Voz de Lara: "no lo dudes, si necesitas ayuda llámame 906...". "Tu ángel de la guarda te espera"

El mensaje está doblemente articulado a nivel de texto y de imágenes. La escenografía celestial y la sensación de indefinición visual de límites se asientan, toman tierra, en el escritorio; así como el discurso angelical y fabuloso de Lara reposa en la confianza y seriedad profesional.

En ningún momento se hace mención a las técnicas adivinatorias (únicamente se ven unas cartas de tarot). Lo que se oferta es compañía, confianza, protección y solución de problemas.

Esta solución viene expresada en un vago lenguaje "quitarte todas tus miedos", que sin ceñirse en ningún momento a la retórica habitual del género, entronca con una serie de creencias populares en las cuales el psicólogo extirpa los miedos y las fobias, como si estos fueran algo ajeno al individuo, al igual que un médico extirpa un tumor (y por supuesto con la misma eficacia). 
Esta oferta publicitaria tan vaga, "te sentirás tan segura de todo y serás inmune a las señales" tan imprecisa e inevitablemente tan holística, supone un paso adelante más en la negación de la dureza de la realidad; Lara de Vina (resulta difícil no ser divina al ser pronunciado) no se presenta como alguien que descifra su destino, sino como un demiurgo generador de realidad, ella se ocupa de " todos tus miedos y ansiedades" e influye sobre tu vida. Tú te pones en sus manos. Aquí aparece otro mito respecto al papel del psicólogo en la ideología popular.

\section{ANUNCIO 3: El firmamento del destino}

Pantalla negra. Sonido de distorsión (ruido blanco) y viento. Aparece el busto de una mujer con los ojos vendados. El busto gira lentamente. Su imagen aparece un poco distorsionada, sobre un gris metálico. Abajo figura la inscripción "906 ..."

Hola, mi nombre es Concha García. Estoy aquí porque quiero contarles el giro que dio mi vida cuando conocí el 'Firmamento del Destino'. Antes me consideraba una mujer insegura, muy inmadura y frágil. Mi vida era una sucesión de días que almacenaba sin saber cómo. Un día una amiga me dio un número de teléfono y me recomendó el 'Firmamento del Destino'. No sé cuando ni por qué me decidí a llamar y mi vida cambió. Ahora me arrepiento de no haberlos conocido antes. Hoy me dirijo a ustedes y les insto a llamar al 906... del 'Firmamento del Destino'. Sus servicios son veinticuatro horas al día. Si contacta con ellos su vida cambiará y tomará el sentido y el rumbo que nunca debió perder.

El discurso cinematográfico del anuncio entronca continuamente con el monólogo de Concha; ella se describe como una mujer insegura, inmadura, frágil. Para reflejarlo, su imagen tiene los ojos vendados, de fondo se oye un sonido distorsionado, se encuentra prácticamente secuestrada o bajo un protocolo de deprivación sensorial. En esas condiciones nos parece inevitable, como mínimo, sentir inseguridad y 
fragilidad. Las vueltas que da incesantemente el busto de Concha parecen repetir esa sucesión de días que almacenaba sin saber cómo. Desgraciadamente, esa trabazón texto - imagen se pierde al final, y la imagen no reproduce el final feliz del soliloquio de Concha.

'El Firmamento del Destino' no se molesta en especificar concretamente qué servicio oferta. Es el hecho de que el anuncio se ubique en un bloque publicitario de tarots telefónicos, precediendo la emisión de un programa de videncia, lo que en vigor nos permite encasillarlo en la modalidad de videncia telefónica, pues nuevamente, no hay ninguna mención a los términos propios del género.

Una vez anclado el tipo de producto, entendemos que ofrecen una suerte de tarotguía espiritual que permitirá dar sentido a la vida de los potenciales clientes, reorientando mediante la videncia o la interpretación, sus existencias sin norte.

El hecho de no delimitar la retórica del spot a la clásica del género, permite a la empresa dar cuenta del nicho de mercado compuesto por tod@ s $1 @$ s 'Conchas Garcías' cuyas necesidades y problemas no se ven aparentemente satisfechos por la trilogía vital básica en la mancia (salud, dinero y amor), sino que sus demandas están complicadas por cuestiones psicológicas y existenciales cuya retórica es mucho más elaborada.

Por otra parte, y por supuesto sin olvidar que vendemos magia, no sólo estaremos ofertando una guía espiritual, sino que el discurso del anuncio entronca con la línea publicitaria de los 'productos milagro' 'cambia-vidas', compresas, lavadoras, cuyo consumo produce instantáneamente un cambio a mejor de la vida del cliente. Esta es la virtud de no ceñir el discurso al pasado, al futuro, o al amor, tan sólo sabemos que ya tardamos en descolgar, sin saber 'cuándo ni por qué' queremos un vago y total cambio en nuestra vida. 


\section{ANUNCIO 4: Tarot sacro}

Voz en off: "Fuego, aire, agua, tierra". Sincronizadas con las palabras en off aparecen imágenes de, respectivamente, llamas, hojas moviéndose, una cascada y dos manos sujetando un puñado de tierra.

La imagen cambia y aparece en escena un plano en el que cinco manos, unas encima de otras, forman una 'piña'. Con esta imagen de fondo, la voz en off dice:

de la combinación de los cuatro elementos y el mejor equipo de videntes nace el tarot sacro.

Un nuevo plano, unas cartas en pantalla, sobre un fondo marino, sirviendo de soporte, en la parte superior e inferior de la pantalla, para el teléfono de contacto 906 y el slogan de 'Tarot Sacro'.

Este anuncio vincula el poder del tarot a los cuatro elementos constitutivos, desde los presocráticos, de todo cuanto se puede encontrar en el mundo.

El anuncio sacraliza el tarot apelando a que su poder reside en dos aspectos. De un lado, el que proviene de la conjunción de elementos que configuran (tradicionalmente) todo objeto encontrable en la realidad, con lo cual se le presupone la capacidad de conocerlo todo, pues está hecho de lo que está hecha cualquier cosa. Por el otro lado, reside su fuerza adivinatoria en la combinación de las capacidades de los miembros del equipo de adivinación (añadiendo un matiz de profesionalidad), que juntos hacen una piña. 
El 'Tarot sacro', de esta forma, se apoya tanto en la mística de lo primigenio (lo que da origen a todas las cosas) como en la práctica de lo grupal (el fin de toda cultura, la socialización).

Este tarot, así garantiza su poder, con lo que el cliente creerá en la verdad de lo que haya escuchado, por una parte, en los elementos de los que emana su omnisciencia, y por otra, en el conjunto de videntes que conocen los mecanismos internos de este tarot.

Con esta comunión de elementos, natura y cultura, el tarot sacro refleja diáfanamente la tradición 'new age', que pretende reconciliar el retorno a los orígenes, con la comunidad (cinco manos formando una piña) y la civilización ('equipo de videntes').

ANUNCIO 5: El tarot íbero

"Vive tu vida sin obstáculos", dice una voz en off. Un individuo vestido de cuero negro con el pelo teñido color rubio, aparece sentado en posición de medio loto sobre un trilito que levita sobre el cielo.

Aparece impreso en la pantalla 'Tarot Íbero' y dos manos muestran unas cartas de tarot sobre un paño negro y una vela. Voz en off: "Tu mejor cómplice". Música étnica.

Se divide la pantalla en tres partes (un chico, un chico, una chica) que dicen respectivamente "yo entiendo", "y yo", "y yo". A continuación, el individuo del comienzo lanza la pregunta: "¿Y tú?".

Voz en off: "Te sorprenderás". Plano de la bandera gay. 
En un primer momento, el anuncio nos sitúa en un contexto de tipo exóticoreligioso. A continuación, sufre un giro y aparecen unos personajes que se entienden entre sí y preguntan al espectador si también entiende. Hay un salto del plano de la adivinación al plano relacional. En este caso se hace evidente la insignificancia del mensaje mántico en relación al interés del servicio como punto de contacto, haciendo una llamada al público gay. El personaje inicial ya nos empieza a dar la idea, la cual es concretada por el uso de la palabra 'entender' en un contexto que la trasforma en código de relación entre personas homosexuales - (si lo entiendes lo entiendes, y si no, es que no entiendes)-. La voz en off hace comentarios que acentúan la complicidad gay, en la cual se da cabida tanto a hombres como a mujeres. El nombre del tarot, 'Tarot Íbero', podría remitirnos ya a la idea de 'macho ibérico' o incluso a la de 'tía jamona'. La circunscripción al público gay se corrobora con un último plano de la bandera del movimiento homosexual.

Nuevamente, la palabra tarot aparece descontextualizada, sirviendo de pretexto a una oferta de relación interpersonal. A pesar de todo no debemos olvidar que se trata de publicidad de servicios mánticos, por lo tanto, la incertidumbre de qué nos deparará el 'Tarot Íbero', no sería gratuita.

ANUNCIO 6: Tarot: la profecía

Voz en off: "No somos profetas, somos las mejores tarotistas y santeras cubanas." "Pregunta y tendrás respuestas convincentes. ¿Qué problema tienes? ¿Amor, dinero, trabajo, sexo? Llámanos y conocerás tu verdad. Somos tus amigas, no nos importa quién seas, en qué trabajas o donde vives, sólo queremos ayudarte. Baraja española, runas, videncia, astrología, llámanos y te sorprenderás: 906 ... 'Tarot La Profecía'. Confía en nosotros. Recuerda, somos las mejores tarotistas y santeras cubanas, más de treinta años de experiencia nos avalan. Recuerda 906 ... 
Durante todo el texto, leído por una voz en off, un plano de una catarata vertiendo agua a un estanque, sirve de fondo, todo semioculto por la fronda esmeralda.

El anuncio se ubica en la línea clásica del género mántico. Enumera las técnicas que suministra para solventar problemas de amor, dinero, trabajo y sexo.

Sin embargo, también aparecen elementos típicamente más modernos (por lo reciente), el énfasis en el origen santero-cubano de las tarotistas sería un ejemplo. También resulta novedoso el interés por los problemas sexuales, así como el deseo de ayuda incondicional ("somos tus amigas, no nos importa quién seas, en qué trabajas o dónde vives, sólo queremos ayudarte"), que sugiere una aceptación, una comprensión, por un lado desde la profesionalidad, pero también desde el calor de la amistad. Esta idea es reforzada por el "confía en nosotros", ya que "conocerás tu verdad", verdad que aparece ilustrada por medio de ese paisaje paradisíaco, que exalta las esencias de la naturaleza primigenia.

Así vemos como el 'Tarot de La Profecía' no se resiste a incluir en su formato algunos de los contenidos del campo del bienestar a través de vías alternativas (espiritualidad, énfasis en lo natural, lo étnico).

\section{ANUNCIO 7: Aura}

Fondo: Un acantilado rocoso se recorta contra el cielo y el mar. Atardece y rápidamente anochece. Sale la luna, emergiendo del horizonte, cortado por el mar. En ese momento hay una lluvia de estrellas y aparece escrito AURA.

Voz en off: "Aura te ofrece en directo y durante las veinticuatro horas".

Música: colchones de sintetizador con sonidos 'new age'. 
Voz en off: "videncia, tarot, astrología, interpretación de sueños".

Cambia el plano - fondo y aparece un ojo, cartas del tarot, los signos zodiacales, etc.

Voz en off: "en el 906 ...".

Un paisaje que evoca la naturaleza en su estado elemental (cielo, mar, tierra) sirve de marco al nombre correspondiente a la titular del tarot (Aura). El momento del día es el ocaso, cuando la luz abandona y se propician los estados de ánimo mas decaídos. Este trasfondo es el que ilumina la lluvia de estrellas que acompaña el nombre. La música de corte 'new age' realza esta situación de incertidumbre.

Un ojo aparece como reflejo del conocimiento suministrado.

El anuncio utiliza la iconografía clásica del ámbito ocultista (signos zodiacales, lluvia de estrellas, un ojo, tonos oscuros, la luna), centrándose en las técnicas mánticas (videncia, tarot, astrología, interpretación de sueños).

ANUNCIO 8: El hombre de la multitud

Una música suave abre el plano. Un hombre vestido de traje y con los ojos vendados se encuentra quieto en medio de la multitud, en la calle. Las personas se desplazan rápidas, están pasadas a alta velocidad.

Voz en off: "En un mundo de ciegos".

Una carta de tarot en primer plano sirve para cambiar la imagen. 
El tipo de antes mueve la boca.

Voz en off: "donde no existen ni viven nuestra voces".

La carta cambia nuevamente de plano.

El individuo está sentado en la mesa de una oficina mientras su jefe le abronca. Ruido de fondo.

Voz en off: "donde todo lo que escuchamos es nulo".

La carta del tarot.

Voz en off: "alguien te escucha, te habla".

Una mujer en primer plano, con los ojos cerrados y los oídos tapados, se los destapa.

Voz en off: "y seguramente te ve".

La mujer abre los ojos.

Voz en off: "Tarot amor" "906 ...".

Cambio de plano.

Voz en off: "Porque no estás solo en el camino a seguir".

El tipo del comienzo se marcha de espaldas a la cámara caminando por la playa. De fondo se oye el sonido del viento. 
El hombre incomunicado, vendados los ojos, encuentra su correlato en los mensajes de aislamiento que lanza la voz en off. Presenta la soledad, la incomunicación, el individualismo, una idea extendida de la disminución de la cercanía entre las personas en las sociedades modernas. El amor se presenta como solución y viene de la mano del tarot. Una mujer, ella si te ve, te escucha; incluso, ¿te consolará maternalmente de las reprimendas de tu jefe, asumiendo el papel de la madre en el Edipo?

El resultado es la vuelta a esa tranquilidad paradisíaca, alejada del mundanal ruido, el personaje se aleja caminando por la playa. Los problemas fueron conjurados.

De nuevo la oferta se centra en aspectos afectivos como compañía, escucha, etc., sin hacer apenas referencia a las técnicas mánticas.

\section{ANUNCIO 9: Anna}

Voz en off: "Tarot, astrología, videncia, interpretación de sueños".

Sonido: viento.

Plano de fondo: un cielo rojo, marciano, una espiral con los símbolos zodiacales, se inserta sobre el cielo.

Voz en off: "ANNA y su equipo esperan tu llamada.", "906 ..." "las 24 horas del día en directo" "906 ...", "confía en nosotros".

En el plano-fondo el cielo torna a azul noche. 
Un cielo rojo, una espiral en con los símbolos del zodiaco, y la enumeración de las técnicas mánticas, sitúan el anuncio en la tradición del género adivinatorio. La noche, lo oscuro, y el nombre del oficiante (Anna) cierran el clima de misterio propio de lo esotérico.

Este tipo de publicidad destaca por su pobreza y la explotación de una iconografía totalmente asumida por el género.

\section{ANUNCIO 10: Octavio Aceves}

Voz en off: "Línea de Octavio Aceves, por fin en vivo y en directo." "Ya puedes llamarle y consultarle en el 906 ..."

Un cartel que reza "línea de Octavio Aceves 906 ..." durante todo el tiempo sobreimpreso en la parte inferior de la pantalla.

Mientras se sucede la lectura de la voz en off se van superponiendo diferentes planos de Octavio vestido de traje y siempre con fondos blancos en los que su busto y su cara, aparecen, se funden unos sobre otros y levitan con los límites totalmente indefinidos, borrosos del casi omnipresente blanco. Una música electrónica de estilo entre 'new age' y 'dance' sirve de fondo sonoro al discurso.

Se detiene la sucesión de planos, la voz en off, la música, y un plano de Octavio en su despacho aparece en pantalla. De fondo, una estantería con libros y él, sentado en su mesa de despacho, dirigiéndose sonriente a la cámara dice: "Para resolvernos todos los problemas personales." En ese momento, en la esquina superior izquierda aparece un letrero: "Servicio atendido por el equipo de Octavio Aceves". 
Volvemos a un plano de los anteriores con Octavio "derretido" en blanco luminoso y la voz en off exhorta "llama ahora".

Nuevamente nos enfrentamos a un discurso cinematográfico que envía mensajes contradictorios. Emergiendo de un fondo blanco, cegador, levitando en el vacío, nos encontramos con un caballero vestido con un riguroso traje corbata, don Octavio Aceves, un sonriente ángel vestido de abogado. La imagen es tan paradójica como la que nos transmitiría el mago Merlín, paseando por un laboratorio de física, pero es este acrisolamiento de elementos aparentemente irreconciliables, una característica fundamental de este anuncio y de la línea publicitaria que representa.

Así, nos venden un servicio que reúne por un lado, la sabiduría y bondad celestiales, representadas en la blancura física del anuncia, fuente de poderes paranormales de adivinación, precognición y sanación, y por otro, la profesionalidad de un trabajador cualificado, que aparece recitando su mensaje, ya sin músicas celestiales, sin blancos almidonados, en su despacho, rodeado de libros y parapetado tras una potente mesa o escritorio.

El texto del anuncio, sin embargo, no encierra contenidos contradictorios, a diferencia de los guiones de anuncios en esta línea (véase 'Lara de Vina'), Octavio apoya con sus palabras exclusivamente, su imagen de profesional de gabinete y nos ofrece "resolvernos todos los problemas personales", sin ninguna mención al universo mágico, al pasado, al futuro, a la salud, al amor o la bola de cristal.

ANUNCIO 11: El ermitaño

Un horizonte rosa con una cuadrícula virtual impresa, se recorta contra el cielo azul. Comienza a sonar una melodía 'techno' de marcado carácter 'espacial'. 
En el fondo del plano, en el centro de la pantalla, se materializa un caballero, vestido como un clérigo, las manos recogidas una sobre otra, da dos pasos y se acerca a la cámara: "Soy el ermitaño, ¿tienes dudas sobre el amor, la salud o el dinero?". Mientras tanto, unas gigantescas cartas de tarot llueven del cielo y reposan al caer a sus pies.

Cambia el plano. Ya sólo aparece el busto del ermitaño recostado contra el cielo, el teléfono de vigor escrito abajo y dice: "No dudes más, llama al teléfono 906... mi gabinete y yo podemos ayudarte."

Un documento aparece recortado sobre un fondo rosa, girando. El ermitaño dice: "Además recibirás gratuitamente los cielos del tarot que rigen tu vida desde tu nacimiento".

Reaparece su busto y dice: "Recuerda, llama al 9064280 80." "Una voz amiga te está esperando".

Utilizando el análisis del anuncio de Octavio Aceves como referente, podemos afirmar que el spot del Ermitaño es el 'negativo fotográfico' del primero.

Es ahora, una escenografía ultramoderna, informática, apoyada por una sintonía de mareado carácter 'techno', la que sirve de marco a un personaje atávico, que se hace llamar 'El Ermitaño' y que viste como un clérigo. Nos enfrentamos nuevamente con el doble discurso, pero esta vez al revés (con respecto al anuncio de referencia): lo que antes era un profesional de la salud, imbuido de poder celestial, es ahora nuestro mago Merlín paseando por un laboratorio de física (en este caso de realidad virtual).

Y con esta ya analizada estrategia, los publicistas aúnan en la figura de 'El Ermitaño' las dotes adivinatorias con la ultramodernidad, pero en este caso el producto 
vendido es radicalmente diferente. Se oferta un adivino en toda regla, en su texto, arropado por una lluvia de naipes de tarot, 'El Ermitaño' pregunta "¿tienes dudas sobre el amor, la salud o el dinero?", haciendo alusión a la trilogía clásica en la mancia. Y al final del anuncio, nos obsequia con los ciclos del tarot que regirán nuestra vida desde nuestro nacimiento. Destino, salud, amor, naipes, son enmarcados en la realidad virtual y colocan a nuestro ermitaño en la línea ideológica que entronca con los movimientos 'new age', aunando las sabidurías ancestrales con la modernidad.

\section{ANUNCIO 12: El rey mago}

Comienza la secuencia de imágenes con un desplazamiento en el espacio. La sensación de movimiento la da el hecho de que las estrellas se "aproximan". Mientras, una música tétrica, que activa la inquietud hace esperable una explosión, que servirá de marco para que en la pantalla adquiera protagonismo un cartel que rece "Tarot en directo".

Siguiendo una cadena de acontecimientos cósmicos, de una explosión surge el círculo astral con los correspondientes signos del zodíaco, a la vez que un mensaje en la parte inferior de la pantalla exhorta a contactar con el teléfono de rigor: "llama ahora".

Signos zodiacales vuelan en una sucesión de imágenes de planetas, mientras música del estilo anterior continúa hasta que el plano se cierra con una imagen en negro.

Una corta secuencia muestra a un rey (caracterizado como el del imaginario popular del medievo) asomado a un balcón en un ambiente oscuro. El plano es en perspectiva desde abajo. A continuación este personaje, el plano cambia a una perspectiva aérea, consulta a otro personaje sobre el contenido de un libro. 
Una nueva secuencia nos introduce a un nuevo marco oscuro: una vidente sobre una bola de cristal parece conversar entre amigable y misteriosa con un cliente. Ambos vestidos como si de una fiesta de etiqueta se tratase. En ella ningún signo en su físico delataría una condición mágica. Una ventana entreabierta que deja intuir la noche en el exterior es lo que preside el decorado.

La situación cambia y la vidente se enfrenta ahora a una mujer también vestida con mucha corrección. La vidente mantiene una actitud de receptividad. Como antes, primeros planos parecen describirnos el interés y la confianza de los clientes en esta vidente.

La escena final será el final de que habrá sido una pequeña historia. En un ambiente que permanece oscuro la cliente se aproxima a una puerta (único decorado en la escena), donde, al abrirla, una sonrisa agradecida acepta un ramo de flores entregado por el primer cliente de la bruja. El teléfono de contacto cierra el anuncio.

La característica que hila todo el anuncio y que podría ser calificador de éste sería "oscuro". Todo se aparece casi en la penumbra.

En anuncio, además, parece que explicita los tres ambientes que en la imaginería popular parecen ser los de más "negrura": la inconmensurabilidad del espacio, lo incomprensible por incuestionable de la más alta esfera de poder -no otra cosa es un rey que lo es por la gracia de dios- y la inaccesibilidad de los mecanismos del amor.

El primer aspecto connotaría el vértigo de lo inabordable, ese conocimiento que escapa a toda comprensión y que sume en la honda desesperanza del no poder hacer nada pues hay fuerzas que escapan a nuestra voluntad y que omiten nuestras acciones pues no encontramos efectos en ellas. Un viaje por el espacio no deja de ser 
moverse para permanecer en el mismo sitio (en la inmensidad estar en cualquier lugar es tan indiferente como no moverte), pero profundamente parece decirnos que tras el movimiento que se ha estado llevando hasta ahora, casi por una suerte que se merece se ha llegado al lugar que se estaba esperando. Hartos de estar-no estar en ninguna parte, un estallido nos ha detenido en el lugar que nos corresponde: frente al tarot.

Ahora prevalecen los aspectos bellos del espacio: imágenes de formaciones cósmicas (planetas, nebulosas) nos ubican en un sitio bello, pero a la vez inaprensible: el tamaño de lo cósmico vuelve inútil cualquier medida de cuantificación, es inútil la ciencia, pues ni puede ni tendría efectos en nuestras vidas. Ese nivel que es metáfora de lo que se escapa a nuestra capacidad está hilado, adquiere sentido -pues eso parece indicar el revoloteo de los signos zodiacales, como entidades reales con contenido suficiente como para explicar que esa inconmensurabilidad tiene un hilo explicativo y que a su vez, por ello, somos explicados-, el círculo zodiacal es símbolo de la perfección, por la figura en sí (el círculo) y porque por fin el cosmos adquiere un sentido en nuestras vidas (el zodíaco). Lo cósmico, lo caótico, tras una explosión toma orden en el conocimiento que transmite el tarot.

Las breves imágenes del rey medieval nos remontan a un doble aspecto. De un lado, sólo el poderoso tiene la facultad de preguntarse sobre el más allá, pues se le presuponen capacidades para encontrar respuestas en él. Es por ello que es quién es: por la gracia divina, que le aparta del resto de los mortales, incapaces de encontrar explicación donde parece no haberla. La perspectiva de abajo-arriba -el rey indagando el espacio- parece permitir ver la vista que tendría cualquier desdichado que no fuera ese rey: vería un ser imponente, con actitud de escudriñar sin temor, con capacidad para explicar pues sólo él, desde una situación preeminente (un balcón en un castillo) ha de encontrar las respuestas que demanda quien no está capacitado siquiera para formular preguntas. La siguiente secuencia parece sugerir 
que ese rey sabe donde está la respuesta. Un entorno cerrado, ambientado con luces naturales -fuego- genera la calidez suficiente como para que, en una perspectiva aérea, fuesen esta vez los astros los que estuvieran confirmando que su sabiduría está contenida en esa persona -iun brujo?- que comunica en un libro lo que se ha de saber.

De esta sencilla manera las secuencias anteriores parecen ser metáforas inconscientes de la secuencia posterior:

La oscuridad permanece, pero esta vez un ambiente cerrado parece protegernos de lo inabordable de la noche que permanece en el exterior de la habitación. Ahora en vez de un rey-sabio hay una vidente-sabia, que a través de una bola en vez de un libro, parece que a un hombre -un campesino que viera antes al rey en el balcón- le anticipa lo que le he de ocurrir. Ahora queda el consuelo, la esperanza, de que esa vidente-rey nos puede comunicar lo que antes era sólo privativo del espacio del castillo, del rey con su magia. Esta vez, sólo por una módica cantidad, las respuestas escritas en "eso" incomprensible del cosmos están al alcance de cualquiera que pretenda vivir, encontrar en la vida, lo que este sujeto espera de ella. Ahora conoce la respuesta y puede ir en paz (carecer de angustia por no saber "qué va a ser de mí"). La mujer de la siguiente secuencia también transmite esa confianza que encontrábamos en el hombre que consultó con anterioridad. No obstante ambos llevan el estilo de ropa que lleva la vidente, quien confía en sí y por eso lo traduce en un atuendo casi de fiesta -allí donde se puede disfrutar-. La sonrisa, como antes, parece explicar que el futuro parece confirmarle a la cliente sus expectativas positivas -pues sólo parecen disponer de futuro quien posee expectativas de cambio-.

En la siguiente imagen ya no hay nada que nos haga intuir un "afuera". Un entorno absolutamente hermético, en el que no hay signos de ningún espacio cósmico -de ninguna pregunta, de ninguna angustia-; un ambiente que recuerda a aquél 
encuentro de confianza entre el rey y el presumible mago a la luz de donde se encuentra lo inamovible, lo escrito en el libro, la confirmación de la sabiduría divina, en donde nada puede invitar a la pregunta pues ya todo está definido.

Efectivamente, en el marco de una puerta, metáfora de lo desconocido, en donde no se puede saber qué hay al otro lado, la chica cliente de la vidente se dirige hacia ella con paso firme y decidido, con sonrisa y sin atisbo de preocupación. Abre, casi sin preguntar(se) por quién será. No cabe la incertidumbre: con la puerta abierta un ramo de flores avanza hacia ella, envuelta ya en felicidad. Ese ramo precede al primer y fornido cliente de la adivina.

Se recuerda a quién hay que llamar. Siempre será demasiado barata la capacidad de poder abrir la puerta sin preocuparse de la posibilidad de que pudiera ser cualquier otro...

Volver al principio del apartado

Volver al principio del artículo

Volver al principio

\section{Categorías publicitarias}

\section{INTERPRETACIÓN DEL CORPUS PUBLICITARIO}

Una vez analizado los contenidos de la publicidad, identificamos aquellos elementos con los que podríamos describir los cuerpos narrativo y gráfico de los diferentes anuncios.

Esta multiplicidad de elementos nos permitirán configurar las categorías relevantes (con significación), considerando la presencia de aquéllos y el grado en que se manifiestan en los diferentes anuncios. No se puede olvidar sin embargo que cada 
anuncio puede contener diferentes combinaciones de los elementos que citamos, y que en cada uno aparecerán con diferentes pesos específicos respecto a otros anuncios.

Así pues, estas categorías no son más que expresiones ideales, por lo que en los anuncios pueden identificarse elementos que diluyen los límites entre una y otra. Con todo, en los anuncios considerados prevalecen las suficientes características significativas de una categoría como para considerarlos pertenecientes a esa en particular (sin más duda que la de determinar en qué grado se manifiestan y qué configuraciones toman los diferentes elementos). Sin embargo esto no quiere decir que determinados elementos sean privativos con exclusividad de una categoría, sino que esos elementos prevalecen sobre otros como más característicos en un determinado anuncio..

\section{ELEMENTOS DESCRIPTORES:}

1. Relevancia de la figura del oficiante:

En ocasiones el servicio ofrecido toma el nombre e imagen representativa de esta figura, de manera que es la sola presencia del oficiante la característica predominante. En otras se alude a los poderes o capacidades mágicas de una persona, pero con la particularidad de que esta figura aparece en la imagen, pero con distintos grados de importancia relativa respecto a otros elementos.

2. No presencia del oficiante:

No es un aspecto más del punto anterior. La ausencia del oficiante revela aspectos de los que se extraen sentidos cualitativamente diferentes en los anuncios. 
3. Referencia -explícita- a las prácticas adivinatorias:

En este punto los elementos descriptores abarcan desde las maneras tradicionales hasta la mención de prácticas más novedosas como las runas.

4. No referencia a las prácticas adivinatorias:

Una vez más la ausencia de una referencia determinada genera un sentido diferente. La ausencia de elementos genera diferencias cualitativas fundamentales.

5. Salud, dinero y amor:

O lo que es lo mismo: el pasado, el presente y el futuro. La oferta clásica y estandarizada de los servicios de adivinación.

6. Componente social-relacional:

Este aspecto de los anuncios recoge aquellas alusiones en las que se hace referencia al marco social y/o sentimental del cliente potencial -normalmente se ofrece un servicio que revitaliza relaciones de amistad-.

7. Vacío existencial:

En algunos anuncios se puede observar la oferta de una orientación existencial (una orientación a todos los niveles). La retórica empleada incide en los tópicos de la modernidad acerca de la vida en una ciudad y la desorientación vital que la vida contemporánea provoca.

8. Elementos oscurantistas: 
Son todos los aspectos intimidatorios, donde se enfatizan la iconografía tétrica y se inducen miedos con elementos -músicas, sonidos, juegos de luces...- que han caracterizado desde siempre el mundo de la magia y lo sobrenatural.

\section{Elementos optimistas:}

Son escenas en las que prevalece la sensación de luminosidad, de claridad (como por ejemplo nubes blancas y rayos de luz que las atraviesan) y en las que se hace referencia a términos como la paz, la sensación de total libertad...

10. Lo primigenio y lo étnico:

Son aquellos aspectos que refieren a los orígenes. En este término entran en juego elementos de creencias y religiones que podríamos considerar más arcaicas, con técnicas propias para influir en la realidad. También cabe considerar otros aspectos como la mención -o aparición gráfica- de elementos de la naturaleza o como la presencia de elementos que cabría calificar como primigenios (tierra, aire, fuego y agua). Con "étnico" tratamos de describir esos aspectos menos contemporáneos de la cultura (más característicos de los primeros estadios del desarrollo social), y que nos hacen mirar a culturas primitivas.

11. Profesionalidad:

Énfasis en la capacitación y preparación del profesional con especial énfasis en aspectos como la seriedad, la confidencialidad, el trato personalizado y el trabajo en equipo.

12. Modernidad: 
Quizá el aspecto más difuso en tanto que es la manera de tratar muchos de los aspectos que iconográficamente pudieran pertenecer a algunos de los puntos anteriores. Es el aspecto de "cientificidad" que se puede dar a ciertas actividades, de manera que en estos anuncios no se hacen referencia a las capacidades de una persona o a las propiedades mágicas de algún objeto material sino que cierto aparataje metodológico vendría a garantizar la veracidad de las conclusiones (como podría hacer una astrólogo en una carta astral, o un chamán en una determinada combinación de hierbas).

\section{CATEGORÍAS PUBLICITARIAS:}

Los elementos anteriores, como se comentó, se agrupan en diferentes configuraciones hasta constituir -prototípicamente- las categorías que nos sirven para clasificar la publicidad, de manera que se puedan identificar los anuncios bajo alguno de las tres etiquetas (Vieja Escuela, Nueva Era y Contactos Terapéuticos) que pasamos a considerar en la siguiente tabla:

\begin{tabular}{|l|c|c|c|}
\hline CATEGORÍAS & VIEJA ESCUELA & NUEVA ERA & $\begin{array}{l}\text { CONTACTOS } \\
\text { TERAPÉUTICOS. }\end{array}$ \\
\hline $\begin{array}{l}\text { Figura del } \\
\text { oficiante }\end{array}$ & $\mathbf{X}$ & $\mathbf{X}$ & $\mathbf{X}$ \\
\hline $\begin{array}{l}\text { No presencia del } \\
\text { oficiante }\end{array}$ & & $\mathbf{X}$ & $\mathbf{X}$ \\
\hline $\begin{array}{l}\text { Referencia a las } \\
\text { prácticas }\end{array}$ & $\mathbf{X}$ & $\mathbf{X}$ & \\
\hline $\begin{array}{l}\text { No referencia a } \\
\text { las prácticas. }\end{array}$ & & & $\mathbf{X}$ \\
\hline
\end{tabular}




\begin{tabular}{|c|c|c|c|}
\hline $\begin{array}{l}\text { Salud, dinero, } \\
\text { amor }\end{array}$ & $\mathbf{x}$ & & \\
\hline $\begin{array}{l}\text { Componente } \\
\text { socio-relacional }\end{array}$ & $\mathbf{x}$ & & \\
\hline Vacío existencial & & $\mathbf{x}$ & $x$ \\
\hline $\begin{array}{l}\text { Elementos } \\
\text { oscurantistas }\end{array}$ & $\mathbf{x}$ & & \\
\hline $\begin{array}{l}\text { Elementos } \\
\text { optimistas }\end{array}$ & & $\mathbf{x}$ & $\mathbf{x}$ \\
\hline $\begin{array}{l}\text { Lo primigenio y lo } \\
\text { étnico }\end{array}$ & & $\mathbf{x}$ & \\
\hline Profesionalidad & & $x$ & $x$ \\
\hline Modernidad & & $\mathbf{x}$ & $\mathbf{x}$ \\
\hline
\end{tabular}

DESCRIPCIÓN DE LAS CATEGORÍAS:

\section{VIEJA ESCUELA}

En esta categoría se reúnen los tópicos de las prácticas esotéricas; todos los "lugares comunes", lo que el imaginario social concibe, tiene cabida en ella. Si bien es cierto que la naturaleza esencialmente cualitativa del estudio publicitario es incompatible con la aplicación de un "peso" a cada elemento componente de una categoría, podemos observar, sin embargo, que el centro sobre el que parecen gravitar los anuncios en esta categoría es el topo "elemento oscurantista".

Cabe esperar que este elemento se manifieste de múltiples maneras (fondos oscuros, cielos nocturnos o extraños, el espacio interestelar, firmamentos extraterrestres, planetas, castillos sobre fondos misteriosos, músicas más o menos inquietantes...), pero con todo será la nota que predomine en la ambientación del anuncio, de manera 
que envuelva la presencia de los demás elementos que, idealmente, consideramos en esta categoría.

En el discurso tradicional, el proceso mágico precisa de un oficiante que medie simpáticamente entre los deseos del cliente y las fuerzas sobre o preternaturales. Esta mediación se realiza en virtud de uno poderes sobrehumanos que posee el oficiante. Esta presencia variará en intensidad, y podrá ir desde una mención oral hasta la exclusiva presencia en la imagen.

Los aspectos a los que responderá este mago en las consultas inciden normalmente en las dos triadas mánticas: salud, dinero y amor, y presente, pasado y futuro.

La primera de ellas (salud, dinero y amor) es evidente que permanece y que tiñe las otras categorías publicitarias, pero en ellas la retórica es más elaborada, empleando psicologicismos y filosofismos que desdibujan la oferta clásica, más genérica, hasta conceptualizaciones bastante más concretas (miedos, problemas, amistad, etc) que no parecen tener cabida en la idea tradicional de mago, que parece mantenerse por encima de aspectos cotidianos como los citados. Así pues, es la segunda trilogía (presente, pasado y futuro) la que parece circunscribirse a esta categoría prioritariamente sobre las demás, pues se presta a generalidades que son más identificativas de un clásico proceso de adivinación.

El otro elemento característico es el arte en cuestión, la práctica adivinatoria en sí, el procedimiento que permite el milagro. Este procedimiento se ofrece como una capacidad exclusiva del oficiante, sea para observar directamente sobre pasado, presente y futuros, o sea a través de la capacidad de entendimiento que tenga el oficiante de los instrumentos (que serían los que permiten conocer el pasado o el futuro). El fenómeno adivinatorio puede residir tanto en una capacidad sobrenatural del propio oficiante (una capacidad interna e incuestionable que le permite la 
interpretación de sueños, la adivinación...), como en los elementos materiales que el mago se limita a "leer" (la posición de determinadas cartas en el tarot, las posiciones de planetas en la astrología...).

La presencia o alusión concreta a alguna de esas artes comunes en la tradición mántica es más propio de esta categoría.

\section{NUEVA ERA}

Supone una actualización (una modernización en un sentido amplio) de aspectos de la categoría Vieja Escuela, una adaptación a algunos de los iconos que caracterizan los valores culturales más contemporáneos (posmodernos por seguir terminología más reciente). En este sentido ofrece por una lado una visión optimista de la vida como un cúmulo de energías a canalizar, y por otro una confianza en el desarrollo de potencialidades personales en términos de perceptividad y comunión con la Naturaleza a través de sus elementos primordiales (aire, tierra, fuego y agua).

El oficiante, en ocasiones, se presenta como alguien versado en los métodos fundamentales y valores espirituales egipcios, persas, chinos, indios, africanos o sudamericanos (yoga, tantra, Reshi, tarot egipcio, babalao, taoismo...). Sin embargo resulta bastante improbable que la asimilación de estas "ciencias tradicionales" se haya llevado a cabo tomando en cuenta sus cosmologías y sus premisas éticas y existenciales, y sus contenidos soterológicos. Este énfasis multiétnico halla su origen en un rechazo hacia la religión, la ética, las normas sociales, así como la estética oficial contemporánea. El origen de esta actitud puede vincularse al interés de las vanguardias artísticas (comienzos del sigo XX) por lo esotérico, que ahora adoptan algunos grupos sociales, pero de manera más superficial.

\section{ORIENTACIÓN VITAL}


Esta categoría, el paquete publicitario al que se refiere, es sustancialemente diferente a las dos anteriores, pues si bien la Vieja Escuela y la Nueva Era permanecen dentro del marco de la adivinación y sus respectivas técnicas, esta categoría se desmarca de tal fenómeno, haciendo poca -por no decir nula- referencia a las prácticas mánticas.

Este tipo de oferta se presenta, o bien como una respuesta a la necesidad de orientación vital del cliente, o bien como un teléfono de contactos. Este último se caracteriza por la no presencia de oficiante, así como por tratar de llenar un vacío existencial a través del enriquecimiento social-relacional de la persona que demanda.

En otros anuncios que caben ser insertados en esta categoría, el oficiante se presenta poniendo el énfasis no en su capacidad (sobrenatural o conocimientos sobre las técnicas que permiten leer los astros, las cartas o los posos de café, por ejemplo) para vislumbrar lo acaecido o lo que ha de venir, sino en su objetividad y profesionalidad a la hora de responder al desasosiego vital de esa persona que acude, de manera que verá colmado los vacíos y tendrá algo que le orientará desde el momento que consulte. Estos anuncios suelen hacer referencia a virtudes y habilidades que podrían ser calificadas de terapéuticas.

Así las dos variantes en esta categoría se desmarcan de la esencia formal del fenómeno adivinatorio, acentuando un estrato profundo que ha ido adquiriendo relevancia en el espectro del fenómeno mántico debido a algunas características que se dan en los estilos de vida moderna y urbana (soledad, falta de comunicación, distancia interpersonal). Esta relevancia de aspectos menos mágicos no es privativa de esta sociedad de la información, o posmoderna, si no que encontramos estos valores que explotan estos anuncios en el auge ocultista en la Europa romántica y prerromántica del siglo XIX. Podemos observar como autores alemanes y franceses de la época (Goethe, Schiller, Balzac) utilizaban libremente las enseñanzas ocultistas 
en sus obras, cuyos temas e ideología reflejaban la esperanza de una "renovatio" personal, una restauración mística de la dignidad y los poderes del hombre.

Esta transformación personal, se realiza como rezan los anunciantes, bien a través de un fortalecimiento o renovación de los lazos sociales del cliente, bien en virtud de una reorientación de su vida.

Un aspecto adquiere especial importancia a este respecto: hemos de guardarnos de identificar esta categoría con un grado elevado de intensidad en la vivencia del fenómeno adivinatorio. No es que los fenómenos inexplicables y mágicos que revelan las cuestiones que son planteadas acaben por dirigir la vida del cliente, sino que esta categoría es una variante en la que se centra en el vacío existencial de la persona, por lo que acaba otorgando importancia accesoria a las técnicas de adivinación. Esta categoría parece llevarnos directamente a las conclusiones obtenidas tras el análisis de las consultas en directo recogidas en Telemadroño.

Esta tendencia de las artes mánticas a asociarse con virtudes psicoterapéuticas encuentre asimismo confirmación en la prensa especializada del gremio, en la que un mismo anuncio puede incluir tanto servicios de tarot, astrología, etc. como métodos para el crecimiento personal, que serán todos ofertados por un mismo oficiante.

NOTA: Este trabajo forma parte de un estudio cualitativo más amplio que incluye análisis del discurso de los usuarios. Por razones obvias de espacio ofrecemos tan sólo la primera parte: análisis de la publicidad. 